\title{
Applications of Molecular Diagnostics: Solid Tumor Genetics Can Determine Clinical Treatment Protocols
}

\author{
Carlos Cordon-Cardo, M.D., Ph.D. \\ Division of Molecular Pathology, Memorial Sloan-Kettering Cancer Center, New York, New York
}

\begin{abstract}
Solid tumor diagnosis is now entering an era in which molecular genetics plays an important role. Clinical trials have shown different responses to various therapies that correlate with molecular alterations. Biological determinants related to treatment response markers aimed at individualized therapies are being defined and implemented. Patients are now being treated based on the profile of molecular genetic alterations in individual tumors. Protocols based on molecular markers will increase the chances for cure by opting for the right management approach. They also will improve, in most situations, the quality of life of patients with cancer, for example by facilitating organ preservation strategies. The molecular characterization therefore has an important prognostic and practical role in diagnosis.
\end{abstract}

KEY WORDS: Oncogenes, Tumor suppressor genes, Tumor markers, Southern blot, Sequencing, Immunohistochemistry.

Mod Pathol 2001;14(3):254-257

The traditional role of the surgical pathologist has been the morphologic evaluation of human tumors in a search of clues for their histogenesis and anticipated behavior. Over the years this quest has benefited from the application of specialized techniques that now have become part of the pathologist's armamentarium. The use of enzyme histochemistry and electron microscopy expanded the primary microanatomical evaluation to include biochemical and subcellular structural features. More recently, cytogenetics, analysis of DNA content, molecular genetic assays, and immunohistochemistry have been added as valuable adjuncts to light microscopy in cancer diagnosis. These meth-

Copyright () 2001 by The United States and Canadian Academy of Pathology, Inc.

VOL. 14, NO. 3, P. 254, 2001 Printed in the U.S.A.

Date of acceptance: December 12, 2000.

Address reprint requests to: Carlos Cordon-Cardo, M.D., Ph.D., Director, Division of Molecular Pathology, Memorial Sloan-Kettering Cancer Center, 1275 York Avenue, New York, NY 10021; e-mail: cordon-c@mskcc.org; fax: 212-794-3186. ods, particularly the latter, have greatly enhanced our ability to precisely define the lines of differentiation of human tumors, this constituting the basis for the current classification schemes. As important as the 'histogenetic' categorization provided by these techniques is, it addresses only indirectly other aspects of human neoplasia that are more relevant to their biologic behavior and response to therapy. These include rate of proliferation, capacity for invasion and metastases, and development of resistance mechanisms to certain treatment agents.

Molecular pathology studies the origins of disease based on the characterization of acquired genetic mutations and alterations of gene products. In this regard, it differs from medical genetics, in which the main objective is to determine the genetic abnormalities associated with inherited disorders and carried as germ-line mutations. Programs in molecular pathology can be conceptualized as "bridges" between clinical and basic biomedical sciences. The translational aspect of this "bridge" is bi-directional, involving the transfer of relevant observations resulting from analyses of primary tumors to basic laboratory studies, as well as the effective transfer of laboratory findings into clinical investigations.

Programmatic goals of molecular pathology in cancer include: 1) to establish a definitive diagnosis, based on recognition of "fingerprints" of unique molecular alterations in specific tumor types; 2) to provide early detection of tumor cells using sensitive molecular techniques, thus anticipating therapeutic intervention; 3) to render prognostic information of clinical relevance, through the assessment of molecular predictors of outcome; and 4) to assist in the selection of individualized treatment regimens, saving unnecessary drug toxicity. Protocols based on molecular markers will increase the chances for cure by opting for the right management approach, and improve the quality of life of patients with cancer.

It is well known that tumors that look alike under the microscope, and that appear clinically similar, may behave in radically different fashions. This fact 
seriously hampers the ability to accurately predict clinical behavior in a given case. Based on molecular pathology investigations, founded on new basic biomedical insights, tumor-specific alterations associated with malignant transformation and markers that correlate with cancer progression are being identified. The compelling requirement now is to bring the significant new scientific breakthroughs and technologic innovations into diagnostic and prognostic strategies. To illustrate the clinical value of applying molecular pathology approaches in onocology, we have selected a few examples that already are being explored at our institution and other centers.

An example of translational studies affecting patient management is that of molecular pathology analyses in pediatric solid tumors. It was some 75 years ago that James Ewing described a small round-cell sarcoma of children and adolescents, a lesion soon after known as the "Ewing's sarcoma." Most sarcomas arising in children and young adult harbor recurrent chromosomal translocations, which serve as specific "molecular signatures" (1). More than $90 \%$ of Ewing's sarcomas contain a fusion of the EWS and FLIl genes $(2,3)$. In the chimeric product, it is postulated that the amino terminal domain of EWS confers strong transactivation efficiency, while the DNA binding domain of FLI1 affects specific target genes. More recently it has been shown that specific subtypes of these translocations have important prognostic significance (4). Patients with type 1 EWS-FLI1 fusion have a significantly better outcome that those with other fusion types, allowing a molecular stratification for individualized treatment. Similar molecular profiles with both diagnostic and prognostic significance are being identified for other tumors (5-7).

In a recent report, RT-PCR assays were used to detect chimeric transcripts specific for major pediatric solid tumors, including peripheral primitive neuroectodermal tumor, alveolar rhabdomyosarcoma, and desmoplastic small round-cell tumor (8). Highly unusual or nonspecific clinical and/or histopathologic findings led to the initial diagnoses of neuroblastoma in three of six patients and desmoplastic small round-cell tumor, leukemia, and carcinoma in one patient each. The final diagnoses after molecular studies were peripheral primitive neuroectodermal tumor in three patients, alveolar rhabdomyosarcoma in two patients, and desmoplastic small round-cell tumor in one patient. These results led to early corrections in the diagnosis in two patients, but four patients received treatment not considered optimal for the neoplasms ultimately diagnosed, including three who, despite presenting with localized tumors that have a $>70 \%$ cure rate with standard therapy, died of disease (8). It is obvious that molecular genetic studies on solid tumors can elucidate the diagnosis in problematic cases. These diagnostic distinctions are now critical, as disease-specific and risk-directed therapies are being implemented.

Another example of a translational effort that is influencing patient management in adult solid tumors is that of identifying abnormalities of certain cell cycle regulators $(9,10)$. Examples dealing with alterations of p53 and p27/Kipl in bladder and prostate cancer, respectively, will be discussed. Clinically, superficial bladder tumors (stages Ta, Tis, and T1) account for $75 \%$ to $85 \%$ of neoplasms, while the remaining $15 \%$ to $25 \%$ are invasive (T2, $\mathrm{T} 3, \mathrm{~T} 4)$ or metastatic $(\mathrm{N}+, \mathrm{M}+)$ lesions at the time of initial presentation. More than $70 \%$ of patients affected with superficial tumors will have one or more recurrences after initial treatment, and about one-third of those patients will progress and eventually succumb to their disease. It is for these reasons that new methods are being developed that aim at the identification and monitoring of patients presenting with high-risk superficial tumors likely to develop recurrent and invasive carcinoma. $\mathrm{Pa}-$ tients with superficial bladder cancer harboring mutations of the TP53 gene and altered patterns of p53 expression have a more aggressive clinical course (11-14). Several studies reported that detection of altered p53 expression was associated with disease progression and death due to bladder cancer $(12,15)$. Moreover, these aberrations were found to be independent predictors of recurrence and survival in several of the referred studies. Based on these results, several groups have designed and implemented clinical protocols aimed at organ preservation. In a recent report, it was suggested that the bladder could be preserved for up to 10 years for patients with tumors confined to the organ (stage T2) who posses wild-type p53 (16).

Additional problems arise when seeing patients who present with invasive disease. First, despite aggressive surgical resection and adjuvant radiotherapy and/or chemotherapy, the overall cure remains in the range of 20 to $50 \%$. In addition, distant micrometastatic disease, unrecognized at the time of initial diagnosis and treatment, occurs in an important percentage of patients and is the major cause of treatment failure and subsequent death. Because selection criteria to determine treatment for a particular tumor in a particular patient are incompletely defined, new biologic determinants are needed for proper selection and monitoring of therapy. It has been reported that mutations and altered patterns of p53 expression, or genes involved in the p53 pathways, occur in an important percentage of patients with advanced bladder cancer, ranging from 40 to $70 \%$ of these cases $(14,15$, $17,18)$. Moreover, it has been reported that such alterations may represent a major cause of treat- 
ment failure and subsequent death $(17,18)$. It is based on these reported data that new protocols are being designed and implemented guided by molecular determinants.

The prevailing model of the cell division cycle is that of a series of transitions at which certain criteria must be met before the cell proceeds to the next phase $(8,9)$. The key players regulating passage through the major checkpoints are a group of heterodimeric protein kinases comprising a cyclin as regulatory element and a catalytic subunit known as cyclin-dependent kinase (Cdk). On cyclin interaction, the complex achieves substrate-specific binding and enzymatic activity. The main target of these protein kinases is the product encoded by the RB gene, or pRB protein, which on phosphorylation releases critical transcription factors, usually represented by those of the E2F family, involved in several processes including DNA synthesis. A further level of negative control is produced by the expression of specific inhibitors of the Cdks, known as cyclin-dependent kinase inhibitors, which bind to and inactivate cyclin-Cdk complexes. The KIP1 gene encodes the so-called p27 protein $(19,20)$. The function/structure relationship of p27 on the complex has been resolved, revealing that p27 embraces the complex, extending into the cyclin prevents binding of the substrate, while indenting into the catalytic cleft removes the ATP, rendering it an inactive enzyme (21).

Tumor-specific mutations of the KIP1 gene are very rare, and initial studies aimed at characterizing KIP1 in primary tumors were discouraging $(22,23)$. However, two basic observations forced to readdress the original working hypothesis that KIP1/ p27 could function as a tumor suppressor gene. First, it was reported that proteasome-mediated degradation of $\mathrm{p} 27$ protein occurred during the cell cycle and that this degradation was increased in a subset of tumors with poor prognosis $(24,25)$. In addition, the generation of a murine model "null" for p27 revealed that knockout mice had a generalized hyperplasia and they were prone to the development of tumors $(26,27)$. It was reported that normal prostate cells had abundant p27 protein and high levels of p27 messenger. However, prostatic carcinomas could be categorized into two categories: those that contain detectable p27 protein and those that have low to undetectable p27 levels. Primary prostatic carcinomas displaying the p27 low or negative phenotypes were found to be biologically more aggressive, based on their association with time to prostate specific antigen failure after radical prostatectomy and reduced survival (28-30). Based on these data, new strategies are being designed to treat and follow up patients with localized prostate cancer.
These examples were selected for presentation because they connote translational opportunities in molecular pathology. The addition of these objective molecular parameters to our diagnostic and prognostic tools will enhance our ability to characterize tumor biology, predict tumor behavior, and to design effective treatment regimens. It should be emphasized that molecular pathology does not signify molecular genetics, and that immunohistochemical approaches are as relevant and informative, when appropriately applied, as DNA-based assays. In sum, it would be impossible to render the kind of patient care pathologists offer without some of these tools. New classification schemes have evolved based on phenotypic characterization and identification of specific molecular "signatures." Examples of these categorizations were first the hematopoietic neoplasms, and now are followed by pediatric tumors and certain solid tumors, such as colorectal carcinomas. Pathology reports containing molecular data of clinical relevance already are being generated in solid tumors. An example is the reporting on breast carcinomas, which includes in most instances steroid receptor status, Her2/Neu expression and amplification, p53 expression pattern, and proliferative index. Significant efforts on immunohistochemical assays, tissue microdissection, and molecular genetic techniques have been critical to achieve such goals. It is expected that the newly developed high-throughput methods, such as expression profiling by microchip technology, will complement our armamentarium of predictive tools needed to address the molecular complexity that characterizes neoplastic diseases. It is expected that clinical protocols based on molecular markers will increase the chances for cure by opting for the most appropriate treatment, improving at the same time the quality of life of cancer patients.

\section{REFERENCES}

1. Ladanyi M. Diagnosis and classification of small round-cell tumors of childhood. Am J Pathol 1999;155:2181-2.

2. May WA, Gishizky ML, Lessnick SL, Lunsford LB, Lewis BC, Delattre O, et al. Ewing sarcoma 11;22 translocation produces a chimeric transcription factor that requires the DNAbinding domain encoded by FLI1 for transformation. Proc Natl Acad Sci USA 1993;90:5752-6.

3. de Alava E, Ladanyi M, Rosai J, Gerald WL. Detection of chimeric transcripts in desmoplastic small round cell tumor and related developmental tumors by reverse transcriptase polymerase chain reaction. A specific diagnostic assay. Am J Pathol 1995;147:1584-91.

4. de Alava E, Kawai A, Healey JH, Fligman I, Meyers PA, Huvos AG, et al. EWS-FLI1 fusion transcript structure is an independent determinant of prognosis in Ewing's sarcoma. J Clin Oncol 1998;16:1248-55.

5. Ginsberg JP, de Alava E, Ladanyi M, Wexler LH, Kovar H, Paulussen M, et al. EWS-FLI1 and EWS-ERG gene fusions are associated with similar clinical phenotypes in Ewing's sarcoma. J Clin Oncol 1999;17:1809-14. 
6. Clark J, Rocques PJ, Crew AJ, Gill S, Shipley J, Chan AM, et al. Identification of novel genes, SYT and SSX, involved in the $\mathrm{t}(\mathrm{X} ; 18)(\mathrm{p} 11.2 ; \mathrm{q} 11.2)$ translocation found in human synovial sarcoma. Nat Genet 1994;7:502-8.

7. Kawai A, Woodruff J, Healey JH, Brennan MF, Antonescu CR, Ladanyi M. SYT-SSX gene fusion as a determinant of morphology and prognosis in synovial sarcoma. N Engl J Med 1998;338:153-60.

8. Kushner BH, LaQuaglia MP, Cheung NK, Kramer K, Hamelin AC, Gerald WL, et al. Clinically critical impact of molecular genetic studies in pediatric solid tumors. Med Pediatr Oncol 1999;33:530-5.

9. Cordon-Cardo C. Mutations of cell cycle regulators. Biological and clinical implications for human neoplasia. Am J Pathol 1995;147:545-60.

10. Sherr CJ. Cancer cell cycles. Science 1996;274:1672-7.

11. Sidransky D, Von Eschenbach A, Tsai YC, Jones P, Summerhayes I, Marshall F, et al. Identification of p53 gene mutations in bladder cancers and urine samples. Science 1991; 252:706-9.

12. Fujimoto K, Yamada Y, Okajima E, Kakizoe T, Sasaki H, Sugimura T, et al. Frequent association of p53 gene mutation in invasive bladder cancer. Cancer Res 1992;52:1393-8.

13. Sarkis A, Dalbagni G, Cordon-Cardo C, Sheinfeld J, Herr H, Zhang ZF, et al. Detection of p53 mutations in superficial (T1) bladder carcinomas as a marker of disease progression. J Natl Cancer Inst 1993;85: 53-9.

14. Dalbagni G, Presti J, Reuter V, Fair WR, Cordon-Cardo C. Genetic alterations in bladder cancer. Lancet 1993;324: 46971.

15. Esrig D, Elmajian D, Groshen S, Freeman JA, Stein JP, Chen SC, et al. Accumulation of nuclear p53 and tumor progression in bladder cancer. N Engl J Med 1994;331:1259-64.

16. Herr HW, Bajorin DF, Scher HI, Cordon-Cardo C, Reuter VE. Can p53 select patients with invasive bladder cancer for bladder preservation? J Urol 1999;161:20-3.

17. Sarkis AS, Bajorin DF, Reuter VE, Herr HW, Netto G, Zhang $\mathrm{Z}-\mathrm{F}$, et al. Prognostic value of p53 nuclear overexpression in patients with invasive bladder cancer treated with neoadjuvant M-VAC. J Clin Oncol 1995;13:1384-90.

18. Cote RJ, Esrig D, Groshen S, Jones PA, Skinner DG. p53 and treatment of bladder cancer. Nature 1997;385:123-5.

19. Polyak K, Kato J-Y, Solomon MJ, Sherr CJ, Massague J, Roberts JM, et al. p27Kip1, a cyclin-Cdk inhibitor, links transforming growth factor-beta and contact inhibition to cell cycle arrest. Genes Dev 1994;8:9-22.
20. Polyak K, Lee M-H, Erdjument-Bromage H, Koff A, Roberts JM, Tempst P, et al. Cloning of p27Kip1, a cyclin-dependent kinase inhibitor and a potential mediator of extracellular antimitogenic signals. Cell 1994;78:59-66.

21. Russo AA, Jeffrey PD, Patten AK, Massague J, Pavletich NP. Crystal structure of the p27Kip1 cyclin-dependent-kinase inhibitor bound to the cyclin A-Cdk2 complex. Nature 1996; 382:325-31.

22. Pietenpol JA, Bohlander SK, Sato Y, Papadopoulos N, Liu B, Friedman C, et al. Assignment of the human p27Kip1 gene to 12 p13 and its analysis in leukemias. Cancer Res 1995;55: 1206-10.

23. Ponce-Castaneda MV, Lee M-H, Latres E, Polyak K, Lacombe L, Montgomery K, et al. p27Kip1: chromosomal mapping to 12p12-12p13.1 and absence of mutations in human tumors. Cancer Res 1995;55:1211-4.

24. Pagano M, Tam SW, Theodoras AM, Beer-Romero P, Del Sal $\mathrm{G}$, Chau V, et al. Role of the ubiquitin-proteasome pathway in regulating abundance of the cyclin-dependent kinase inhibitor p27. Science 1995;269:682-5.

25. Loda M, Cukor B, Tam SW, Lavin P, Fiorentino M, Draetta GF. Increased proteasome-dependent degradation of the cyclin-dependent kinase inhibitor p27 in aggressive colorectal carcinomas. Nature 1997;3:231-4.

26. Nakayama $K$, Ishida $N$, Shirane $M$, Inomata $A$, Inoue $T$, Shishido N, et al. Mice lacking p27(Kip1) display increased body size, multiple organ hyperplasia, retinal dysplasia, and pituitary tumors. Cell 1996;85:707-20.

27. Kiyokawa H, Kineman RD, Manova-Todorova KO, Soares VC, Hoffman ES, Ono M, et al. Enhanced growth of mice lacking the cyclin-dependent kinase inhibitor function of p27(Kip1). Cell 1996;85:721-32.

28. Yang RM, Naitoh J, Murphy M, Wang HJ, Phillipson J, deKernion JB, et al. Low p27 expression predicts poor diseasefree survival in patients with prostate cancer. J Urol 1998; 159:941-5.

29. Cote RJ, Shi Y, Groshen S, Feng AC, Cordon-Cardo C, Skinner $\mathrm{D}$, et al. Decreased expression of p27/KIP1 is associated with increased recurrence and decreased survival in men with stage C prostate carcinoma. J Natl Cancer Inst 1998;90:916-20.

30. Cordon-Cardo C, Koff A, Drobnjak M, Capodieci P, Osman I, Millard SS, et al. Distinct altered patterns of p27 ${ }^{\text {Kip } 1}$ expression in benign prostatic hyperplasia and prostatic carcinoma. J Natl Cancer Inst 1998;90:1284-91. 